\title{
Deformation and Recrystallisation Textures of Polycrystalline Nickel
}

\author{
J. POSPIECH†, J. JURAT, A. MÜCKLICH $¥, K$. PAWLIK† and \\ M. BETZL
}

(Received February 11, 1983)

The development has been analysed of the primary recrystallisation texture in samples of polycrystalline nickel rolled to various degrees of reduction. A great similarity between the texture characteristics of copper and nickel has been found. Regularities of cube texture development were established and compared with results of texture and microstructure investigations obtained by other authors.

\section{INTRODUCTION}

The deformation and recrystallisation textures of polycrystalline nickel and the accompanying structures have been so far the subject of but a few studies, e.g. Wasserman and Greven (1962), Truszkowski et al. (1966), Vishnyakov et al. (1977), Truszkowski et al. (1978). This is probably due to the relatively infrequent applications of pure nickel. The stacking fault energy of nickel lies in the range of high values, roughly similar to that for copper. Hence, we observe a similarity between the characteristics of the deformation textures of both metals. This was manifested by the results of the analysis of the formation of the texture of nickel within a wide range of deformations, taking into consideration the non-homogeneity of texture, as shown by Truszkowski et al. (1978). The available literature does not provide us

\footnotetext{
$\dagger$ Institute for Metal Research, Polish Academy of Science, Cracow.

$\ddagger$ Zentralinstitut für Kernforschung der Akademie der Wissenschaften der DDR, Rossendorf.
} 
with any quantitative data about the recrystallisation texture. In the present paper we discuss the textures of primary recrystallisation of nickel and the corresponding rolling textures for some selected states of deformations. The analysis is based on the orientation distribution functions (ODF) calculated by the vector method known from the work of Ruer and Baro (1977), which in comparison with the generally known methods of series expansion (Bunge, 1969; Roe, 1965) allows us to obtain a more reliable approximation of ODF by reducing the erroneous fluctuations caused by the so-called ghost effect (Matthies, 1980, 1981; Jura et al., 1980; Pospiech et al., 1981).

\section{MATERIAL AND METHODS}

Polycrystalline nickel of $99.94 \%$ purity $(\mathrm{Ni}+\mathrm{Co}$ ) (already used in an earlier work by Truszkowski et al., 1978) was examined. An annealed sheet about $4 \mathrm{~mm}$ thick with orientation distribution close to random and mean grain size equal to $100 \mu \mathrm{m}$ was subjected to unidirectional cold rolling to $88.9 \%$ rolling reduction. In order for the texture development to be as homogeneous as possible rolling was carried out under conditions in which $1 / \mathrm{h}=1.5 \div 2.0[1$ - contact length of sheet with rolls, $\mathrm{h}-$ thickness of the sample].

Samples of 30.6,64.7 and $88.9 \%$ rolling reduction were sealed in quartz tubes [ $10^{-2}$ T.r.r vacuum], and annealed in a silicate furnace for $1800 \mathrm{~s}$ at various temperatures. For samples obtained in this manner the characteristics of the progress of recrystallisation was determined using magnetic measurements of the coercive force and partly also with the application of stereological methods (Ryś, 1970). This allowed us to establish the temperature of the completion of primary recrystallisation which for successive reductions was $650^{\circ}$ and $625^{\circ}$, respectively, and for the greatest reduction it was found within the interval $575 \div 600^{\circ} \mathrm{C}$. For rolled and recrystallised samples the pole figures of the planes $\{111\}$, $\{200\},\{220\}$ and $\{311\}$ were measured using the X-ray method. Additionally, neutron diffraction measurements were carried out which allowed us to check the homogeneity of the deformation texture and to secure a more reliable (from the point of view of statistics) estimation of the mean texture.

\section{RESULTS}

From the measured pole figures ODF was calculated as a basis for 
a

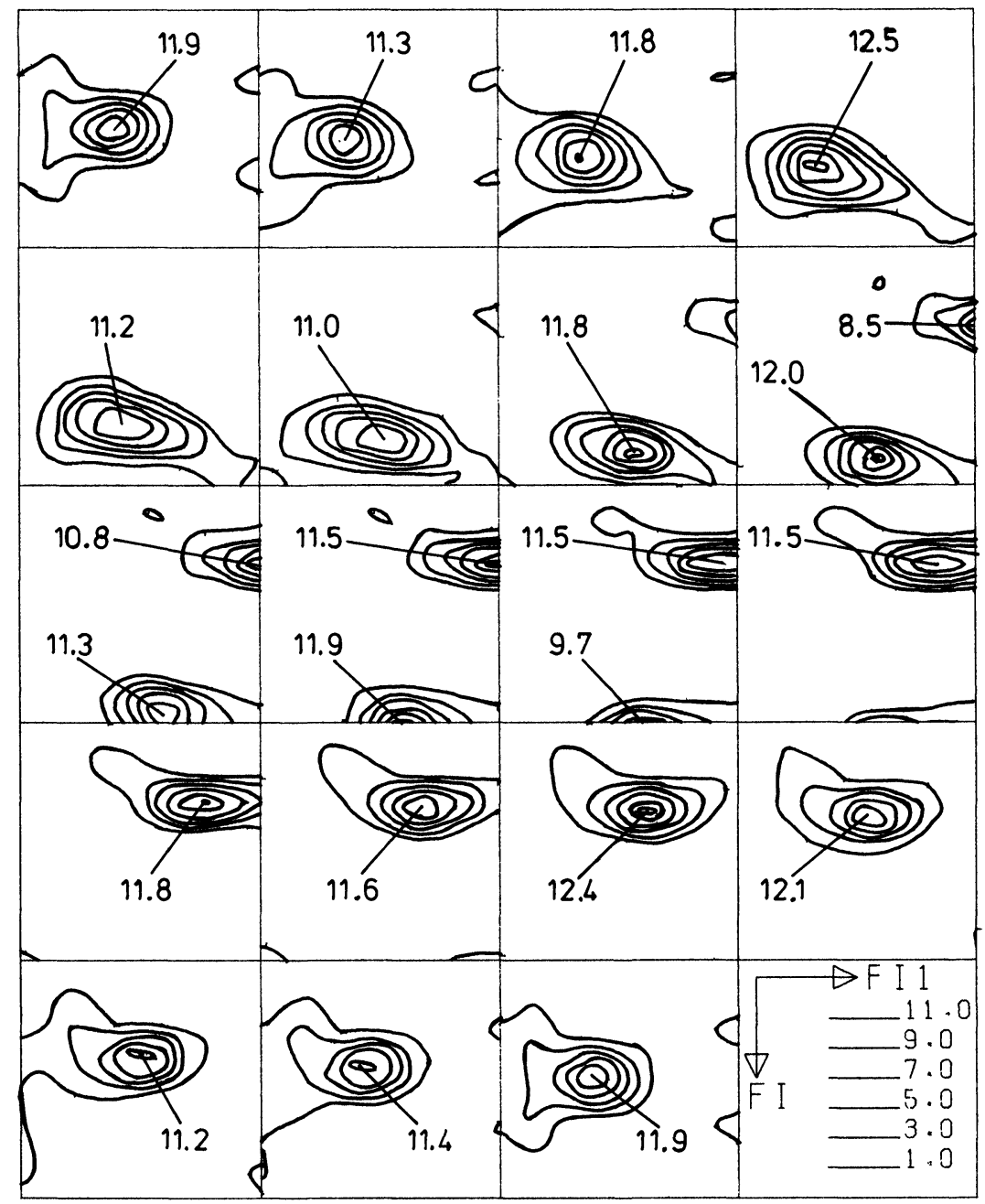

FIGURE 1 ODFs for nickel: a) cold rolled to $30.6 \%$ reduction, b) after recrystallisation annealing. 
b

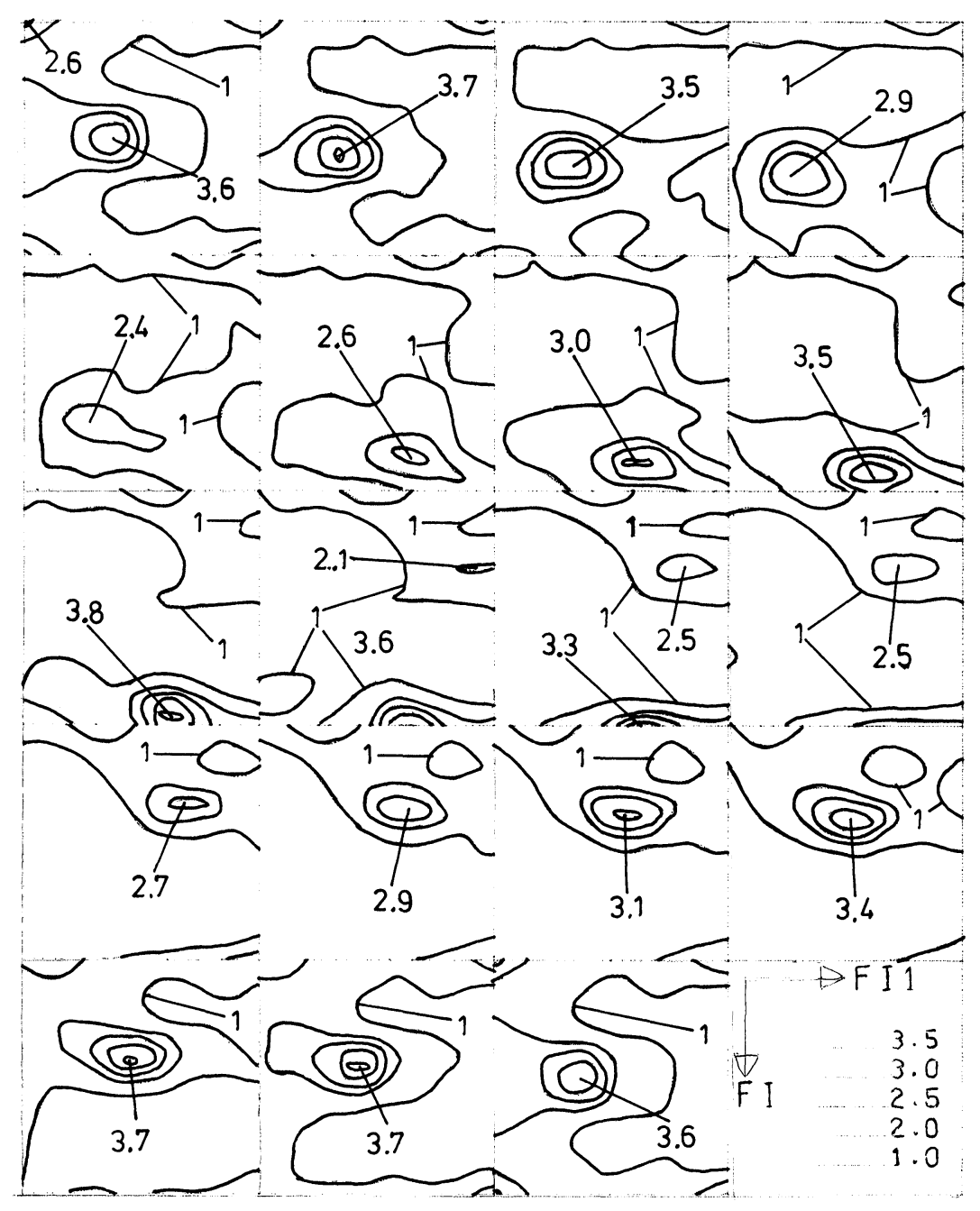




\section{a}

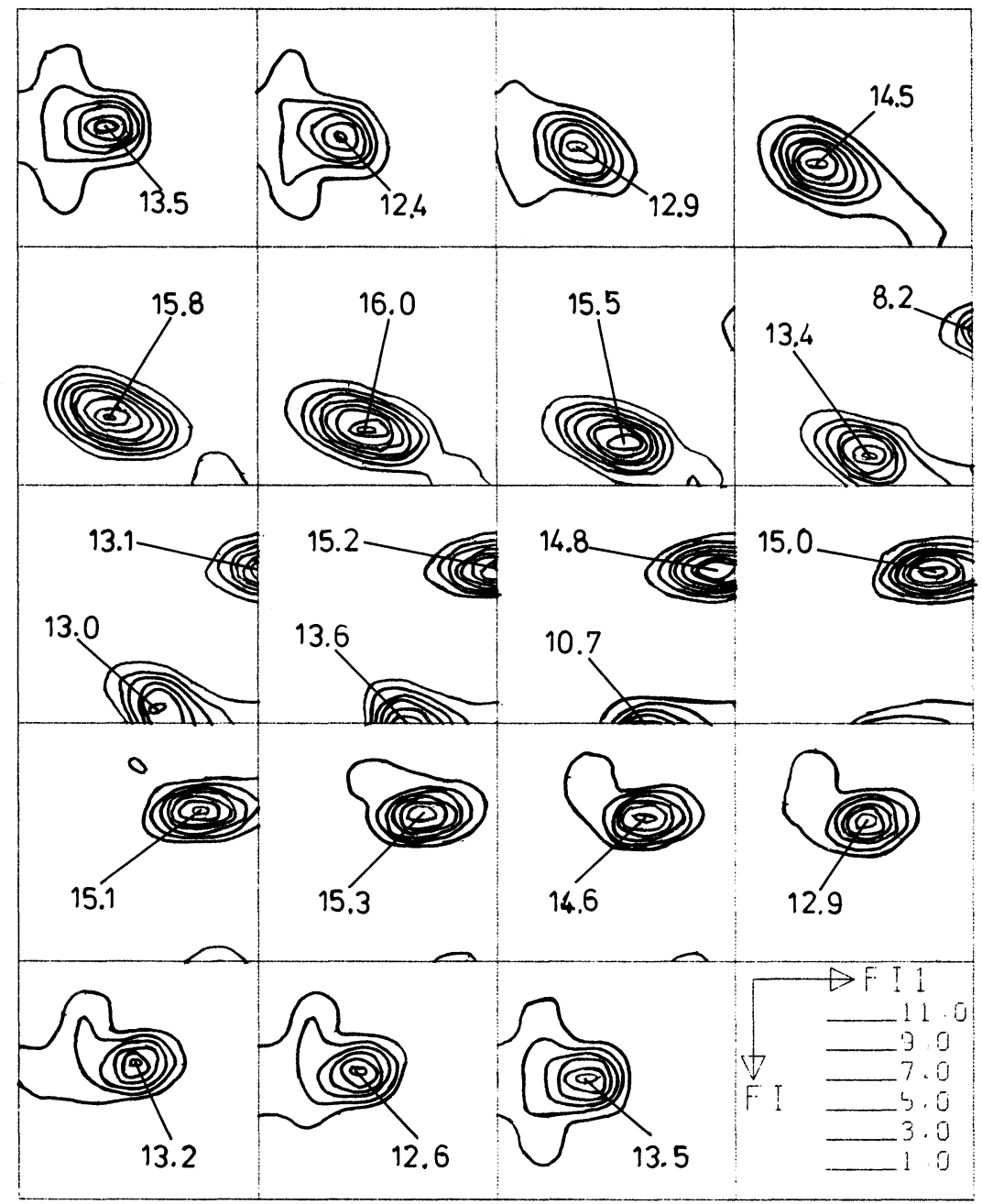

FIGURE 2 ODFs for nickel: a) cold rolled to $64.7 \%$ reduction, b) after recrystallisation annealing. 
b

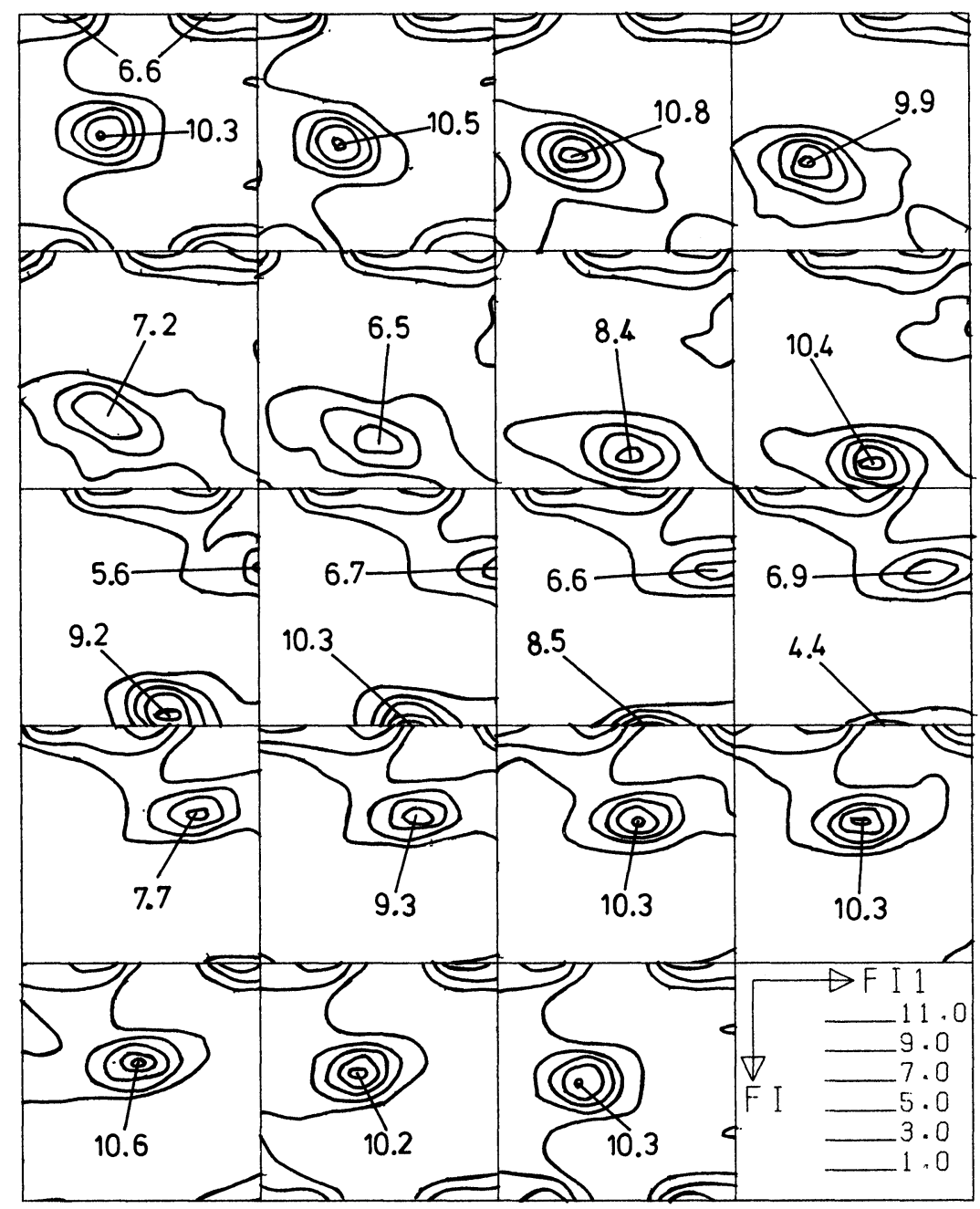




\section{$\mathbf{a}$}

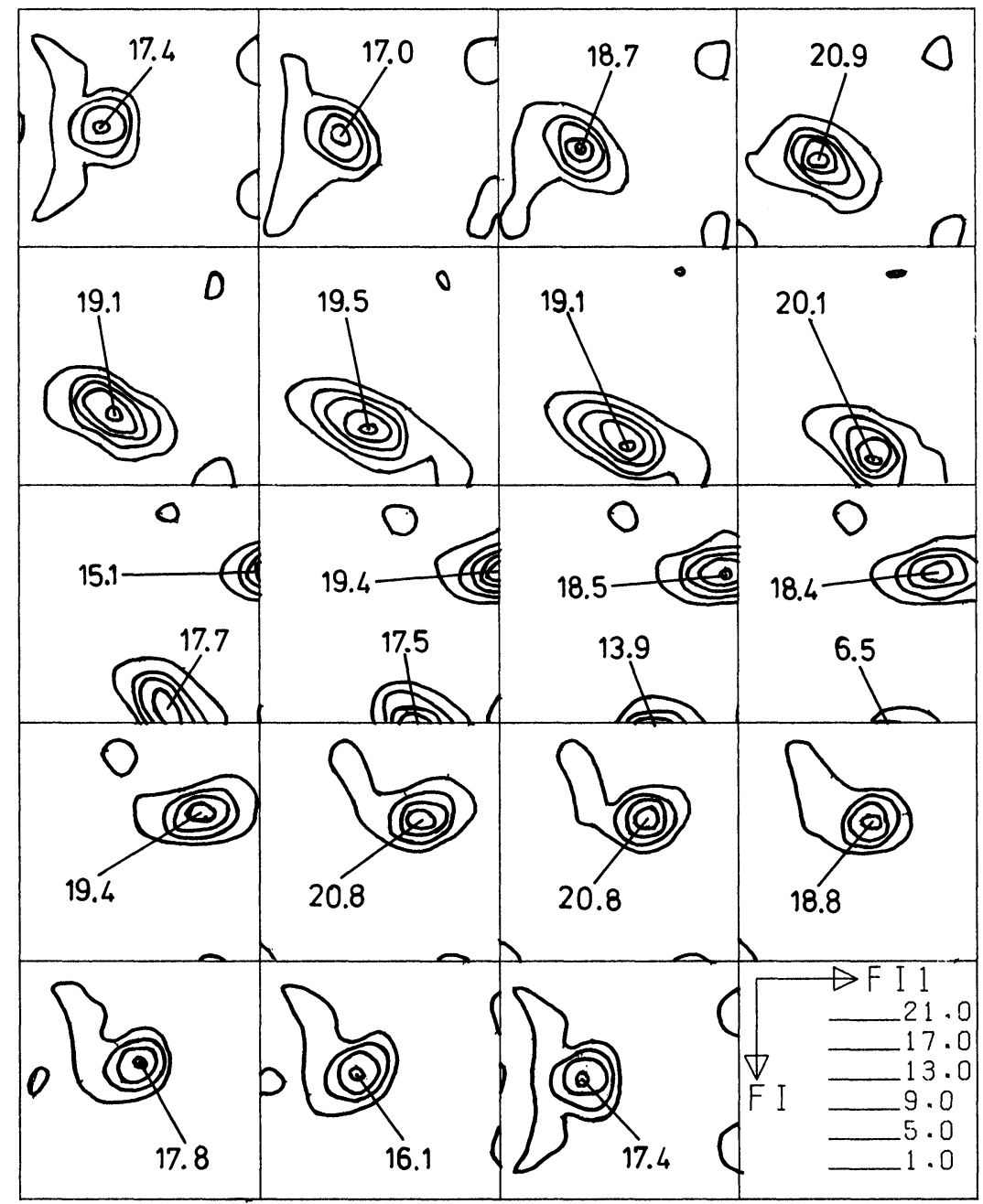

FIGURE 3 ODFs for nickel: a) cold rolled to $88.9 \%$ reduction, b) after recrystallisation annealing. 
b

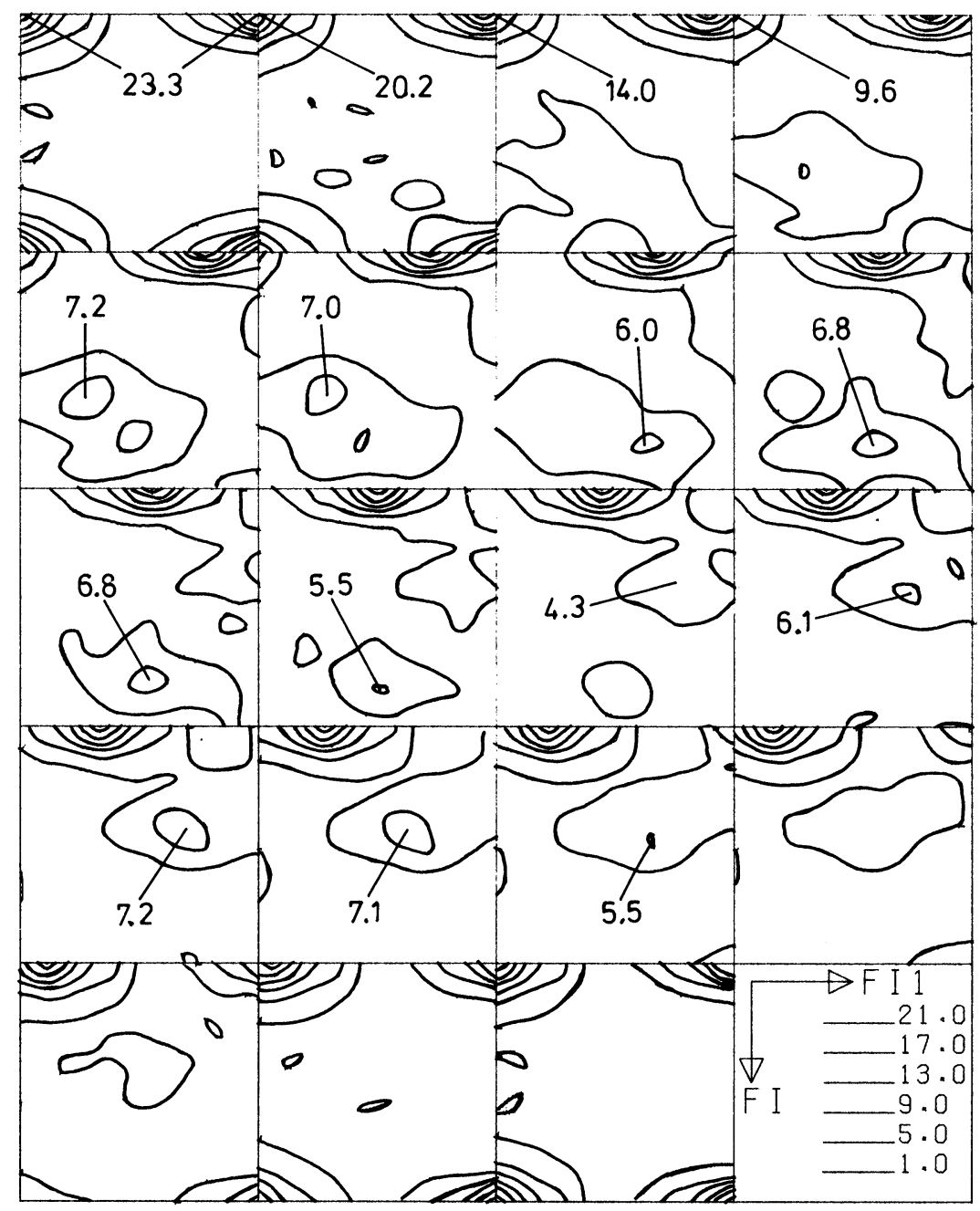



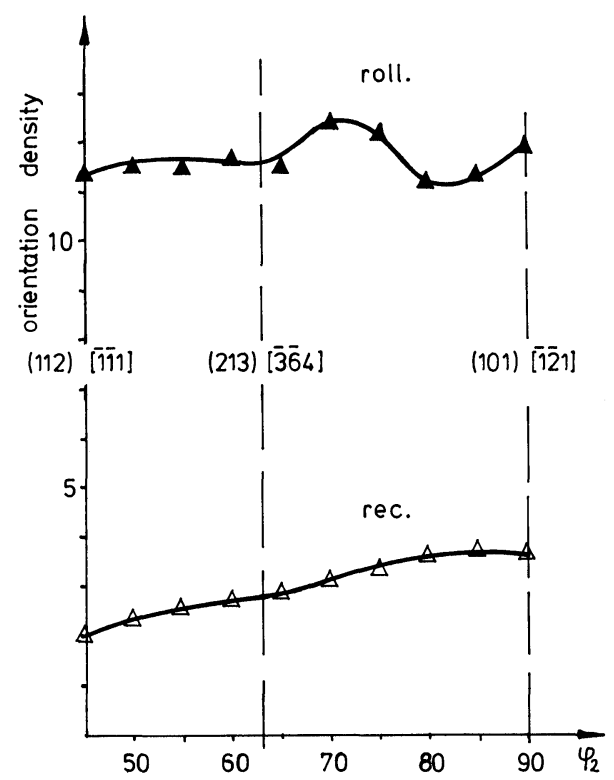

a

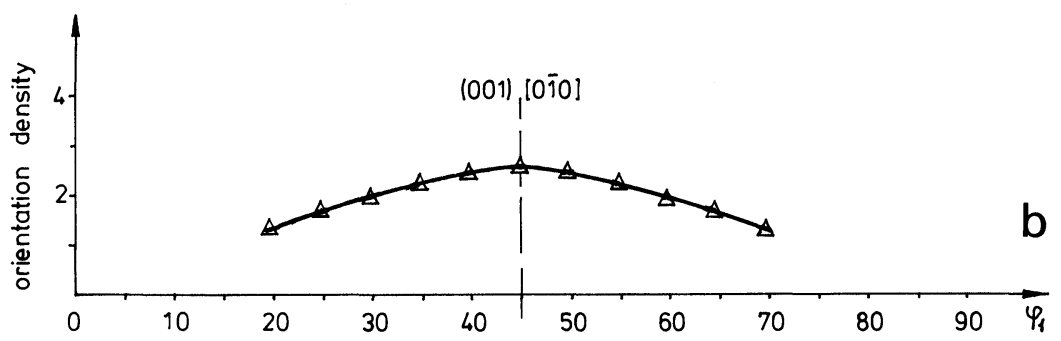

FIGURE 4 a) Orientation density along the skeleton line for nickel cold rolled to $30.6 \%$ reduction $(\Delta)$ and after recrystallisation $(\Delta)$. b) Profile of the orientation densities in section $\varphi_{2}=\Phi=0^{\circ}$ with the cube-position.

texture analysis. In the present paper the ODFs of nickel were determined for states after the deformations of $30.6,64.7$ and $88.9 \%$ reduction. The corresponding ODFs after primary recrystallisation were also determined. The ODF is represented by contour lines of constant values in the space of Euler's angles in the cross-sections $\varphi_{2}=$ const, every $5^{\circ}$ in Figures 1a, 2a and 3a for deformed states, and in Figures 1b, 2b and $3 \mathrm{~b}$ - for states after primary recrystallisation, respectively.

In Figures 4a, 5a and 6a are shown the profiles of the orientation 

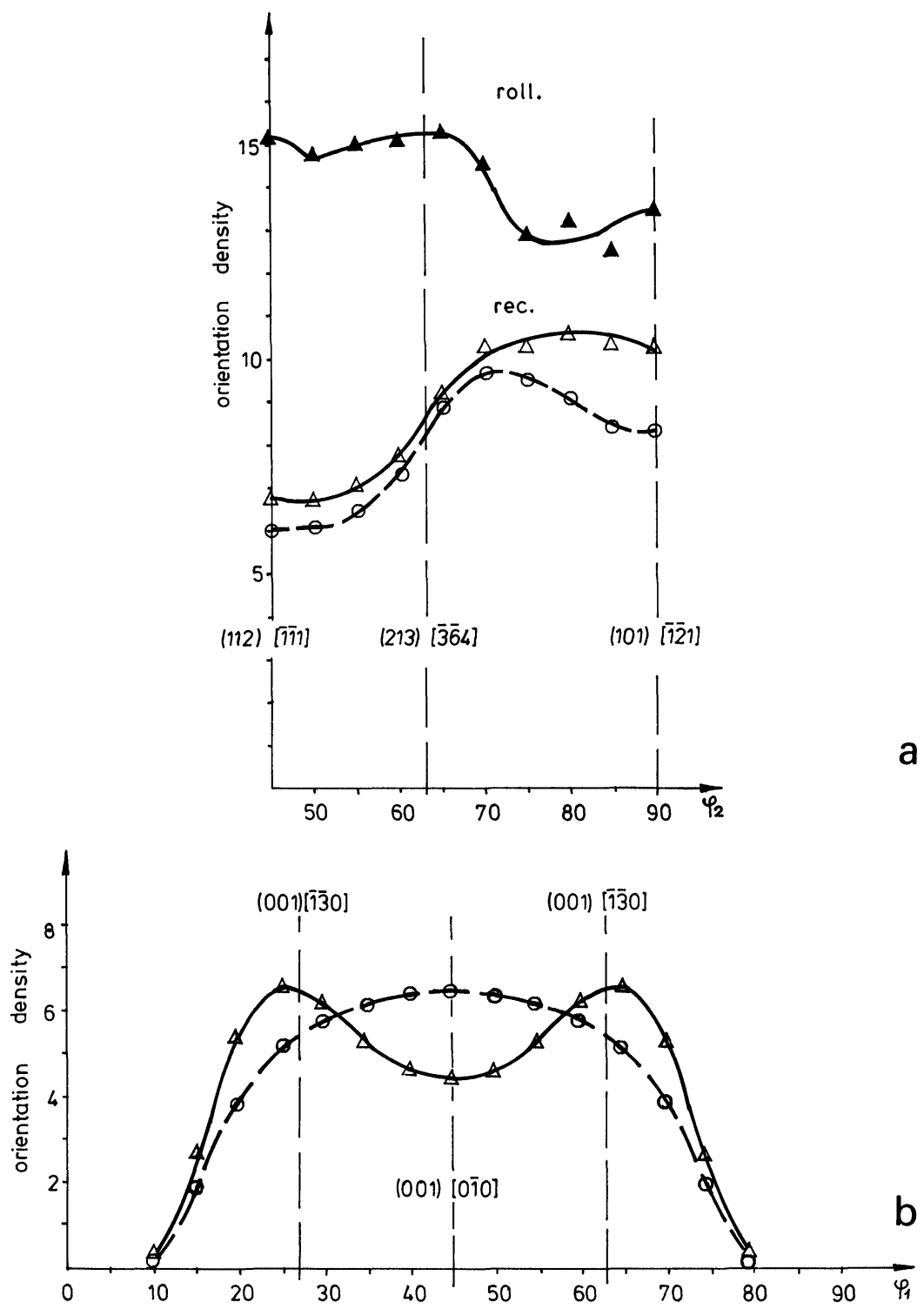

FIGURE 5 a) Orientation density along the skeleton line from X-ray diffraction (full line) for nickel cold rolled to $64.7 \%$ reduction $(\Delta)$ and after recrystallisation $(\triangle)$ also from neutron diffraction (dashed line o). b) Profiles of the orientation densities in section $\varphi_{2}=\Phi=0^{\circ}$ with the cube-position; X-ray diffraction (full line), neutron diffraction (dashed line). 
distribution along the skeleton line running through the positions $\{112\}\langle 111\rangle-\mathrm{C},\{123\}\langle 364\rangle-\mathrm{S},\{110\}\langle 112\rangle-\mathrm{B}$; for a state following recrystallisation the profiles of the orientation distribution in the surroundings of cube orientation are also presented in Figures $4 \mathrm{~b}, 5 \mathrm{~b}$ and $6 \mathrm{~b}$.

In the recrystallised state following $64.7 \%$ reduction (Figures $5 \mathrm{a}$ and $5 b$ ) there appear differences in the shapes of the profile of the orienta-

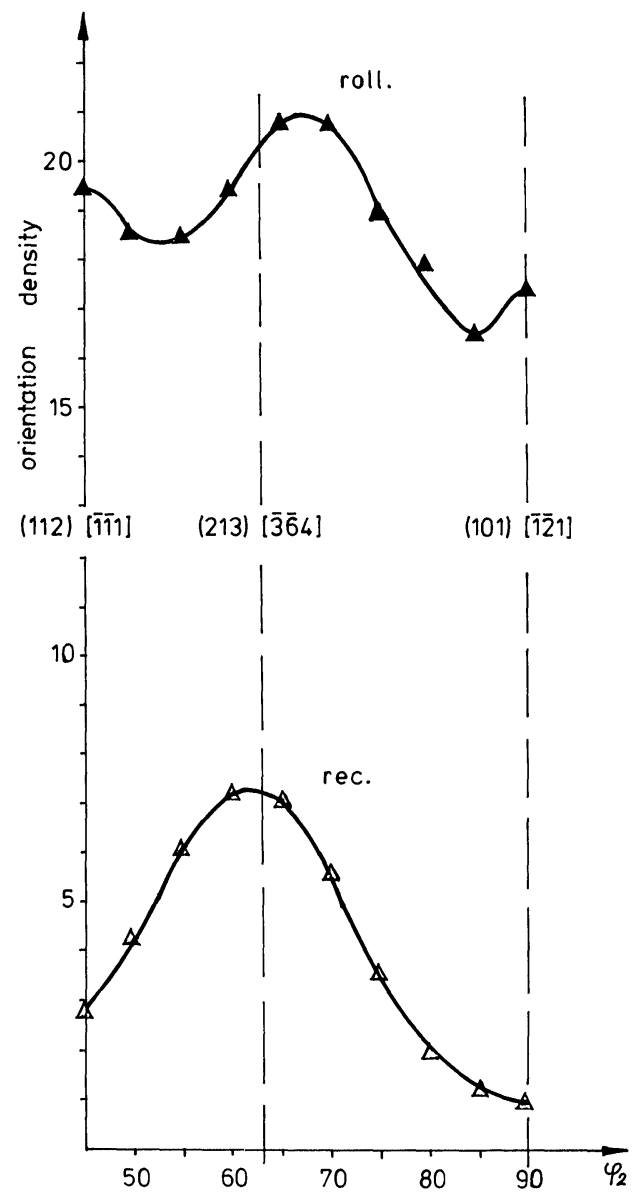

a

FIGURE 6 a) Orientation density along the skeleton line for nickel cold rolled to $88.9 \%$ reduction $(\Delta)$ and after recrystallisation annealing $(\Delta)$. b) Profile of the orientation densities in section $\varphi_{1}=\varphi_{2}=45^{\circ}$ with the cube-position and its twin (221) [122]. 


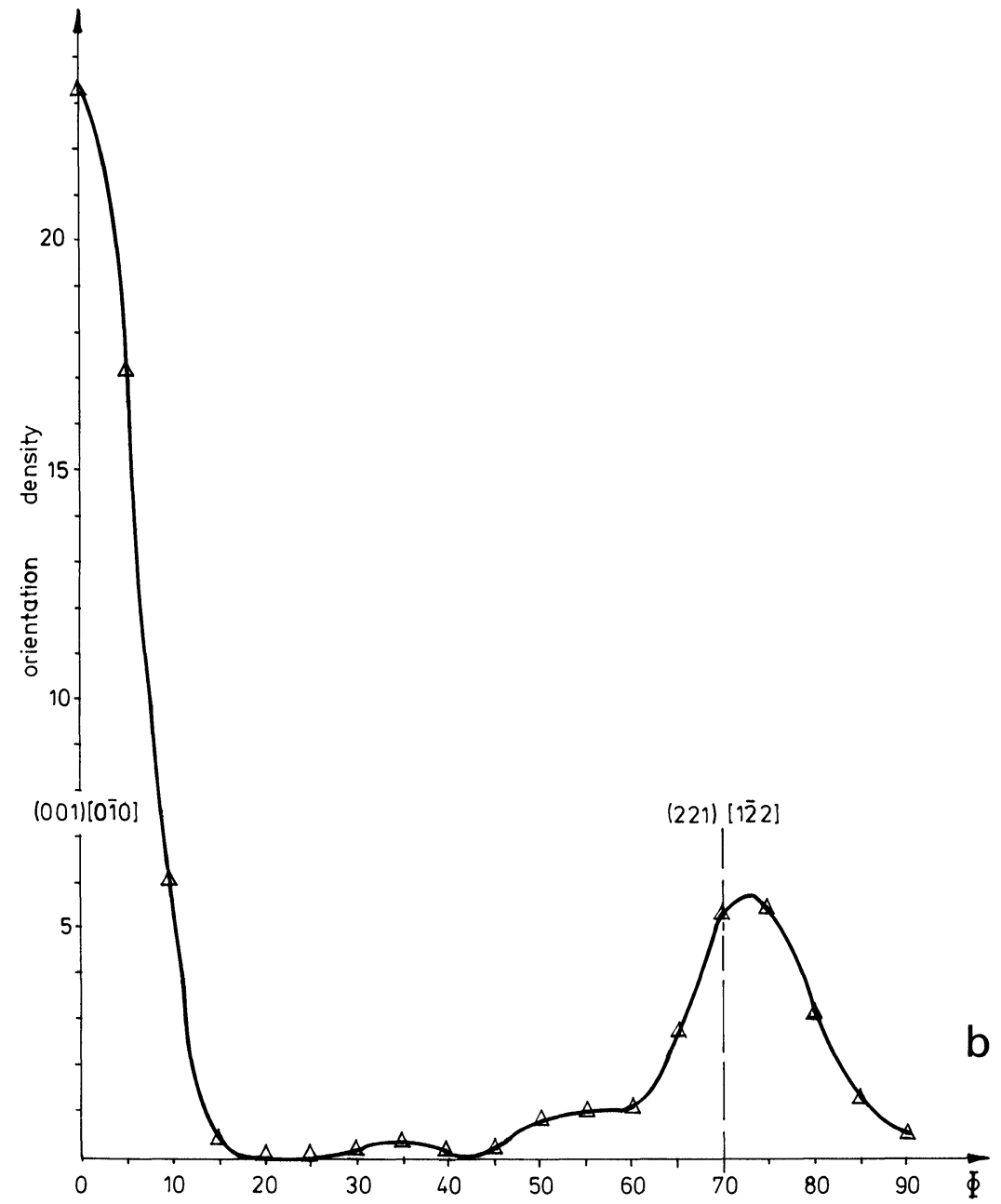

tion density obtained using the X-ray method (continuous line) and that obtained by the neutron diffraction technique (dashed line). This effect can be explained by the non-homogeneity of texture throughout the thickness of the sample.

The observed development of rolling texture is typical for nickel (as well as for copper). With increased degree of reduction along the skeleton line, the three components C, S, B are strongly marked. Among 
them the highest maximum after the final stage of deformation is seen for the component $\mathrm{S}$.

In the textures of primary recrystallisation there occur components observed in the rolled material but in a more diffused form. For 30.6 and $64.7 \%$ reductions they still occur as the main components besides the rather weak cube components. After $88.9 \%$ reduction in the recrystallisation texture the cube component is the dominating one, occurring together with its twin $\{122\}\langle 221\rangle$ and the position S.

When comparing the recrystallisation texture with the deformation texture for successive reductions, we note, after recrystallisation, firstly the loss of the component $\mathrm{C}$. Along the skeleton line we observe first (i.e. for $30.6 \%$ reduction) a broad maximum which includes the range between the positions $\mathrm{S}$ and $\mathrm{B}$. For greater reductions $(64.7 \%$ and $88.9 \%)$ after recrystallisation the orientation density also decreases in the position B, so that, finally, (after $88.9 \%$ ) only the component $\mathrm{S}$ can be observed on the skeleton line (Figure 6a).

\section{DISCUSSION}

The development of texture in rolled nickel was described in greater detail in an earlier paper by Truszkowski et al. (1978). The results shown there confirm the predicted far-reaching similarity between the texture of nickel and that of copper, known from several studies (Bunge et al., 1971, Virnich, 1979; Pospiech and Lücke, 1978).

The maxima formed in the positions $\mathrm{C}, \mathrm{S}, \mathrm{B}$ constitute the main components of the texture of rolled nickel and are usually defined as the components of a copper-type texture. The results of quantitative analysis are an indication that the participation of the component $S$ is, as a rule, greater then that of the components $C$ and $B$, both in copper and in nickel. Table 1 shows, by way of example, the volume ratios (the intensity) of components of the rolling texture for copper after $95 \%$ reduction (Virnich, 1979) and for nickel after $89 \%$ reduction

TABLE I

Volume ratios $(\%)$ of rolling texture components for copper (Virnich, 1979) and nickel (Truszkowski et al., 1978).

\begin{tabular}{cccc}
\hline & C & S & B \\
\hline $\mathrm{Cu}$ & 25.5 & 42.1 & 29.5 \\
$\mathrm{Ni}$ & 24.4 & 43.0 & 32.6 \\
\hline
\end{tabular}


(Truszkowski et al., 1978). It is easy to see that the respective values are close to each other.

The ODFs obtained for states after primary recrystallisation indicate that for small reductions the orientations of the recrystallisation nuclei are contained within the range of privileged orientations which occur in the state following the rolling, since the components of the recrystallisation texture correspond to the components of the rolling texture. At the same time the privileged character of the cube orientation becomes evident.

With increasing deformation in the structure of the material there appear increasingly more inhomogeneities such as transition bands or, with greater deformations, also shear bands. They constitute the source of numerous new nuclei able to grow with a wide orientation spectrum. The obtained results, however, indicate that during recrystallisation the privileged ones are the cube-oriented nuclei, which seem to grow at the cost of the matrix of $\mathrm{C}$-orientation. We observe here a close similarity to the behaviour of copper. The changes in the texture during annealing of copper rolled up to $95 \%$ rolling reduction were quantitatively analysed by Virnich (1979) and Virnich et al. (1978) who showed that the intensity increase of the cube component (observed already at the early stage of annealing) occurs simultaneously with a decrease in the intensity of the $\mathrm{C}$ and $\mathrm{B}$ components while the $\mathrm{S}$-component remains relatively stable. The contribution of the S-component decreases only after a longer annealing time after which a significant increase of the cube component intensity is also observed. The occurring regularities in the behaviour of the matrix orientation correspond to the results of the analysis of the topography of the orientation distribution of copper rolled to $95 \%$ rolling reduction (Haessner et al., 1983). As it is shown by these results, the areas with orientations close to $S$ occur at the regions within which the differences in the orientations of adjacent measurement points (at intervals of $0.5 \mu \mathrm{m}$ ) are mostly small, whereas the areas with orientations $\mathrm{C}$ are as a rule adjacent to those featuring wide differences in orientation. This is an indication that the C-oriented matrix is distinguished by a great density of the inhomogeneities of the rolling structure.

From the point of view of oriented growth, the cube-oriented nuclei are not favourably oriented with respect to the matrix of the orientation $\mathrm{C}$, unlike the case of matrix $\mathrm{S}$, for which to a good approximation, the relation $40^{\circ}\langle 111\rangle$ holds. The results obtained in this paper would thus point to the fact that while the recrystallisation texture is being 
developed, the oriented nucleation is an essential factor with privileged cube orientation. As an interesting confirmation of this fact we may quote the results published recently by Ridha and Hutchinson (1981). They contain explicit data concerning the nucleation of cube orientation inside the inhomogeneities of structure, such as the transition bands. Simultaneously, in another type of inhomogeneity, in the shear bands, which are likely to appear at higher degrees of deformation in metals of copper-type texture (i.e. also in nickel), among the orientations of the growing grains no cube orientation has been found.

The data presented in the paper allow us, in principle, only to state that there exist great analogies between processes of development of deformation as well as of recrystallisation textures in nickel and copper.

From the observed regularities it may be seen that at small rolling reductions, from the yet scarce inhomogeneities which consist of the developing transition bands, nuclei of cube-orientations arise during recrystallisation, leading to a weak maximum in the recrystallisation texture (Figure 4b). At high rolling reductions the density of inhomogeneities increases, with a wide spectrum of orientations of nuclei potentially able to grow. However, cube-oriented nuclei which are distinguished at a given type of structure inhomogeneity, being the first ones able to grow, precede in time the possible development of nuclei of different orientations.

After small reductions, the growth of recrystallised grain proceeds mainly at the cost of the matrix of orientation $\mathrm{C}$, which is distinguished by a great density of inhomogeneities. There appears a weak cube component. The participation of the cube component, however, increases markedly after greater deformations, when simultaneously a greater decrease in the participation of the component $\mathrm{S}$ is observed. This phenomenon can be explained by the fact that with increased reduction the probability increases that a growing grain of a cube orientation will meet an S-oriented matrix with which it forms the $40^{\circ}\langle 111\rangle$ relation favouring growth. The participation of the component $\mathrm{S}$ in the deformed material is then the dominating one as compared with the participation of other components.

\section{CONCLUSIONS}

The results obtained show that there is a great similarity between characteristics of textures in nickel and copper. This concerns both rolling texture and that of primary recrystallisation. 
The development of recrystallised grains in nickel proceeds first of all at the cost of the matrix with the orientation $\{112\}\langle 111\rangle$, and secondly, with increasing deformation, also at the cost of the matrix with the $S$ orientation $\sim\{123\}\langle 364\rangle$, which is in agreement with the results of Virnich (1979) and Virnich et al. (1978) for copper. The observed regularities show that oriented nucleation also plays a role in the formation of the recrystallisation texture with the components of the deformation state and the cube orientation. We assume after Ridha and Hutchinson (1981) that the cube-oriented nuclei are formed in the inhomogeneities of structure of a definite type (in the transition bands). In the orientation spectrum of potential nuclei developed from inhomogeneities of various types, the cube-oriented nuclei are the first to attain growth ability. Again, with increasing deformation the probability also increases of meeting the favourably oriented matrix, i.e. the $S$ orientation $\sim\{123\}\langle 364\rangle$, the participation of which in the material is the greatest.

\section{Acknowledgements}

The authors would like to thank Dr M. Blicharski and Mgr K. Szwiertnia for reading the manuscript and for valuable discussions and assistance. The cooperation of Prof. J. Ryś in establishing the recrystallisation temperatures using stereological methods is also gratefully acknowledged.

\section{References}

Bunge, H. J. Mathematische Methoden der Texturanalyse. Akademie-Verlag, Berlin (1969).

Bunge, H. J., Tobisch, J. and Sonntag, W. J. appl. Cryst. 4, 303 (1971).

Haessner, F., Pospiech, J. and Sztwiertnia, K. Mater. Sci. Eng. 57, 1 (1983).

Jura, J., Lücke, K. and Pospiech, J. Z. Metallkde 73, 714 (1980).

Matthies, S. and Pospiech, J. phys. stat. sol b97, 547 (1980).

Matthies, S. ICOTOM 6, Proc. of the Sixth Int. Conf. on Textures of Materials, Tokyo, Vol. I (1981) p. 276.

Pospiech, J. and Lücke, K. Acta Met. 26, 1709 (1978).

Pospiech, J., Ruer, D. and Baro, R. J. appl. Cryst. 14, 161 (1981).

Ruer, D. and Baro, R. J. appl. Cryst. 10, 458 (1977).

Ruer, D. and Baro, R. Adv. in X-Ray Anal. 20, 187 (1977).

Ridha, A. A. and Hutchinson, B. ICOTOM 6, Proc. of the Sixth Int. Conf. on Textures of Materials, Tokyo, Vol. I (1981) p. 112.

Ridha, A. A. and Hutchinson, B. Acta Met. 30, 1929 (1982).

Roe, R. J. J. appl. Phys. 36, 2024 (1965).

Ryś, J. Wstęp do metalografii ilościowej. Wydawnictwo Ślask, Katowice (1970) (in Polish). Truszkowski, W., Latkowski, A. and Król, J. Mem. Scient. Rev. Met. 63, 951 (1966).

Truszkowski, W., Pospiech, J., Betzl, M. and Jura, J. ICOTOM 5, Proc. of the Fifth Int. Conf. on Textures of Materials, Aachen, Vol. I (1978) p. 253.

Virnich, K. H., Köhlhoff, G., Lücke, K. and Pospiech, J. ICOTOM 5, Proc. of the Fifth 
Int. Conf. on Textures of Materials, Aachen, Vol. I (1978) p. 475.

Virnich, K. H. Thesis RWTH-Aachen (1979).

Vishnyakov, Ya. D., Vladimirov, S. A., Serebryanyi, N. S. and Slavov, V. I. Fiz. Metallov $i$ Metallovedenie 43, 871 (1977).

Wassermann, G. and Greven, J. Texturen metallischer Werkstoffe, Springer-Verlag (1962). 